\title{
Key-risk factors on quality and safety of donated foods in the food aid supply chains: A theoretical framework
}

\author{
${ }^{1}$ Kussaga, J.B. and Luning P. A ${ }^{2}$ \\ ${ }^{1}$ Department of Food Technology, Nutrition and Consumer Sciences, College of Agriculture, Sokoine University of \\ Agriculture, P.O. Box 3006, Morogoro, Tanzania. \\ ${ }^{2}$ Food Quality and Design, Department of Agrotechnology and Food Sciences, Wageningen University, Axis Building \\ 118, Bornse Weilanden 9, 6708 WG Wageningen, The Netherlands. \\ *Corresponding Author's Email:kussaga15@yahoo.com or kussaga@suanet.ac.tz
}

\begin{abstract}
This article presents a theoretical framework that could be applied to provide an insight on the impacts of key-risk factors on quality and safety of donated food along the food aid supply chains. Donated food comes from various countries, produced for different purposes, stored and transported over the long chains to several locations under variable conditions and handled by numerous people often with restricted knowledge on proper food handling. Although there are various reports on the deficiencies in quality and safety of donated food, there is yet a restricted knowledge on where and how quality and safety of donated food could be affected. A technomanagerial approach has been used to develop a theoretical framework to give insights on the risk factors that could impact quality and safety of products along the food aid supply chains. History of donated food products, intrinsic product properties and characteristics of the national food control system were identified as the key-risk factors impacting quality/safety of donated food along the production chains in the donating countries; whereas food legislation, infrastructure and resources, and management and administration of the food control system are the major quality and safety influencing factors at points of receipt. Lastly, intrinsic product properties, qualities of the workforce, nature of the distribution infrastructure, and complexity of the supply chain were identified as the key-risk factors on quality and safety of food during distribution in the receiving countries. This theoretical framework could be used by food aid receiving countries to make informed decisions on the status of imported donated food products and provide relevant distribution and storage requirements to ensure that the intended recipients get quality and safe food products.
\end{abstract}

Keywords: theoretical framework, key-risk factors, national food control system, food aid, donated food quality, food laws, food aid distribution

\section{INTRODUCTION}

Different studies have discussed effects of food aid in economical perspectives with restricted emphasis on safety and quality aspects of donated food. It has been often reported that food aid creates disincentives for small farmers in recipient countries by depressing food prices, distorting markets, discouraging overdue policy reforms and fostering dependency (Kripke, 2005; Young and Abbott, 2005; Barrett and Maxwell, 2006; del Ninno et al., 2007; Gelan, 2007; Bezu and Holden, 2008; Zant, 2012; Garg et al., 2013). Food aid is defined as an international provision of food commodities, usually surplus from donor countries to another needy country to assist the country in meeting its food needs(Gardner and Rausser, 2002; Rupiya, 2004; Barrett and Maxwell, 
2007). It has been a critical element of international response to recent emergencies in Africa, Asia, Central and Eastern Europe, Latin America and Oceania (Barrett and Maxwell, 2006; De Angelis et al., 2007). These regions are experiencing stagnant or even declining food production per capita (Rupiya, 2004; Barrett and Maxwell, 2007) and experience frequent natural (such as earth quakes, floods and volcanic eruptions) and mad-made disasters (like political and ethnic conflicts) (Rupiya, 2004). The decline in food production is however, attributed to factors like re-current droughts, poor soil fertility, high incidences of pests and diseases, poor production technologies, civil and political conflicts, which pose difficulties for farmers to engage in farming activities (Zerbe, 2004; Tusiime et al., 2013).

Despite the fact that globalisation of food trade has focused attention on strengthening measures to ensure quality and safety of food, there is very little emphasis on quality control and safety assurance of donated food (Marchione, 2002). Although vulnerable populations (e.g., severely malnourished, the immune-compromised, pregnant women and elderly) have particular food and nutritional needs, such needs are not always addressed by most of the donated food products (United States Government Accountability Office, 2011; Webb et al., 2011). The food aid donating countries lack consistency in food fortification and enrichment policies and practices (Dexter, 1996). As a consequence, there is an increasing reporting of deficiencies in quality and safety aspects of donated food (Marchione, 2002; Hoddinott et al., 2003; United States Government Accountability Office, 2011; Webb et al., 2011).

There is restricted knowledge on where and how food quality is negatively affected along the food aid supply chains. Ineffective quality controls within the food aid supply chains (United States Government Accountability Office, 2011) including the points of receipt in receiving countries could increase the risk of accepting poor quality and unsafe donated food products. Also, discussions on the use of genetically modified crops for food aid demonstrate that there are not yet applicable international food safety standards for all situations (Zerbe, 2004). However, it is recommended that foodstuffs given to recipients in situations of crisis should respect the ethical, social, cultural and religious norms of what is edible and what is not (Violette et al., 2013).

To our best level of knowledge, there is no theoretical framework developed to provide insights on the key-risk factors that may have impacts on the quality and safety of donated food along the supply chain. Therefore, the objective of this study is to develop a theoretical analytical framework based on literature that can be used as a basis for systematic analysis of key-risk factors on quality and safety of the donated food along the supply chains. Food aid recipient countries could use this scientific framework to analyse cases and identify critical risk-factors on quality and safety of food products in food aid supply chains as a basis for improvement. This paper starts by a brief analysis of reported safety and quality problems of food aid, characteristics of donated food supply chains, factors affecting quality of donated food, in-depth description of the analytical framework and finally, conclusions.

\section{Quality, safety and nutritional problems of donated food reported in literature}

Although food aid plays a vital role in assisting people in need, there are several reports on poor quality, safety and targeting of the food aid (Mathys, 2004; Barrett and Maxwell, 2006; United States Government Accountability Office, 2011). Micronutrient deficiencies including iron, vitamin $A$ and iodine have been reported on beneficiaries that entirely depend on the food aid like the refugees (United States Government Accountability Office, 2011). Serious nutritional and health problems in emergency victims have been also reported (Marchione, 2002; Barrett and Maxwell, 2007). Particularly, outbreaks of pellagra, beriberi and scurvy have been observed among the food aid beneficiaries in Angola refugee camps (United States Government Accountability Office, 2011). Also fortified blended foods for food aid do not meet the nutritional needs of infants and young children between the ages of 6 and 24 months (Fleige et al., 2010). The maize donated to the needy in Burundi, Democratic Republic of Congo (DRC) and Rwanda caused diarrhoea and children could not eat it (Reed and Habicht, 1998). As a consequence, the donated maize were sold to purchase other preferred food products (like cassava flour), iron rich-products and to diversify their diets (Reed and Habicht, 1998). Moreover, donated food is often expired, adulterated, and or contaminated because of long storage duration associated with poor storage conditions and extended periods of transportation; typically 4-5 months (Wareing et al., 1993; Landman, 1999; Marchione, 2002; Barrett and Maxwell, 2006; Barrett and Maxwell, 2007). Furthermore, it is associated with high costs of delivery to recipient country (Barrett and Maxwell, 2007; del Ninno et al., 2007; Violette et al., 2013). Besides the international food aid, food donations to homeless people in the UK was also reported to be of poor nutritional quality as energy, potassium, calcium, vitamin $C$, vitamin $A$, zinc and magnesium content were below the dietary reference value (Pelham-Burn et al., 2014).

\section{Characteristics of donated food supply chains}

Food aid is the international provision of food or funds/goods to be exchanged for food (Murphy and McAfee, 2005). It must be concessional i.e. must be either free or provided to the recipient at a cost lower 
146 Afr. J. Food Sci. Technol.

than the commercial price of the food involved (Murphy and McAfee, 2005). Food assistance by a government or private agency to local citizens, such as the food stamp program in the U.S.A, does not count as food aid. There are three categories of food aid; program, project and emergency food aid (Murphy and McAfee, 2005).

Program food aid involves the transfer of food from one government to another as a form of economic support (Murphy and McAfee, 2005). It was purposely designed and used to dispose commodity surpluses in donor countries that could not find a commercial market. In the 1960's it was the major type of food aid, however, it has now shrank to less than $22 \%$ of the total food aid (Murphy and McAfee, 2005; Harvey et al., 2010).

The project food aid is provided on a grant basis for hunger-related development, disaster relief or nutrition programmes (Murphy and McAfee, 2005). It is largely channelled through multilateral agencies (like World Food Programme, WFP) and non-governmental organisations (NGOs). Its share has dropped to about $12 \%$ of the total food aid (Murphy and McAfee, 2005; Harvey et al., 2010). It is focused on direct distribution of food to people living with hunger. The major types of project food aid are food for work and school feeding programmes (Murphy and McAfee, 2005; Harvey et al., 2010).

The emergency food aid is intended for direct, free distribution to people facing famine or an acute shortage as a result of natural or man-made disasters (Murphy and McAfee, 2005). Although overall food aid volumes have been declining, the emergency food aid has been considerably increasing (i.e. more than 66\%) due to recurrence of natural calamities (like drought, earthquakes, floods, landslides and typhoons) and manmade disasters (civil wars and political unrests) (Webb, 2003; Murphy and McAfee, 2005; Harvey et al., 2010). For the scope of this paper, our focus will be on the emergency food aid.

Food aid could be sourced through direct transfers, triangulation and local/regional purchases. Direct transfers are food aid donations that originate in the donor country. This mode contributes to the majority $(>70 \%)$ of all food deliveries (Murphy and McAfee, 2005). Direct food aid transfers are a form of tied aid (i.e. food sourced in the donor country by the donor-country contractors). For instance, $75 \%$ of the food aid budget of the largest donor (i.e. U.S.A) of food aid is tied-up to the costs of procurement, processing (fortification and bagging) and shipping handled in the U.S.A, whereas, $90 \%$ of Canadian food aid budget is directed to the cost of procurement and handling of commodities within Canada (Murphy and McAfee, 2005). Triangulation purchases refer to purchases of food in one country (not the donor) for use as food aid in another country. It contributes to less than $15 \%$ of all food aid (Murphy and McAfee, 2005). The majority ( $>70 \%)$ of the food is purchased from developing countries. Local purchases correspond to the procurement of food for use of food aid in the recipient country. Although it is still a small part of total food aid contributions (Murphy and McAfee, 2005), the support for local purchases is growing (Harvey et al., 2010). It is often observed that local/regional purchases is more cost effective and faster (Harou et al., 2013; Lentz et al., 2013), provide foods which are more culturally appropriate and/ or preferred, nutritious (vitamin content, calories, fat and protein content, omega 3 fatty acids and gluten free) and less time to cook (Harou et al., 2013; Violette et al., 2013).

\section{Factors affecting quality and safety of donated food}

The food aid supply chain is a long and complex chain involving several actors, transportation means and extended storage periods while serving the most vulnerable people. There is restricted knowledge on where, when and how quality and safety of donated food could be affected along this complex supply chain. Moreover, appropriate control measures, quality and safety standards, food control authorities and food legislation are lacking to appropriately control incoming food by most food aid receiving countries (Wareing et al., 1993) coupled with inadequate distribution conditions. Since food aid is delivered during the emergencies, it indicates that little or no control on quality/safety is most likely. Therefore, there is a need to identify potential risk factors on quality and safety of donated food products. This section will analyse the literature and identify possible key-risk-factors that could impact the quality and safety of donated food along the supply chain. The donated food supply chain is divided into three distinct parts; (1) processing and delivery (transport) of products by donating countries affecting initial quality, (2) quality control of incoming products at receiving countries affecting accepted quality level (called intermediate quality), and (3) storage and distribution performance in the receiving countries before products finally reach the target groups, which results in final quality. Quality of food products typically decays over time; thus, time is a critical factor in food supply chains (Rahman, 2007; Luning and Marcelis, 2009). The quality and safety of donated food depends on quality control during production (in the donating countries), receipt (at point of entry in the receiving countries) and distribution (storage and transport) in the receiving countries. At each stage of the food aid supply chain quality is normally affected.

\section{Factors influencing quality/safety of donated food during production in donating countries}

The way food products were handled (produced, processed, stored and transported) along the production chain in the donating country or country of origin (for 
triangulation purchase) could influence the quality/safety. Besides, the production characteristics of the food aid (i.e. history of the products) (Zerbe, 2004), the nature of the products (i.e. sensitivity of the intrinsic properties for deterioration) (Rahman, 2007) and characteristics of the national food control system of the donating country could also play a role in quality and safety of donated food products (FAO/WHO, 2004; Hopper and Boutrif, 2007). Poor quality control at point of receipt could result into acceptance of poor quality or rejection of good quality products.

\section{History of donated food products}

History of donated food products refers to where the food was produced, processed and or imported/purchased including all associated processes. This could be affected by the food safety policies and food legislation of the donating countries, storage and distribution conditions, and time between production/processing and export. Different countries have various policies and legislations towards food safety (Hopper and Boutrif, 2007); while some countries have national food safety policies with strict food legislation and regulations covering the whole food value chain, others do not or have inadequate legislation. Lack of national food safety policies and strict food legislation indicates that proper control and monitoring of the food chain are not always possible. Storage and distribution conditions in donating countries or country of purchase could influence the initial quality of donated food, because, typical storage conditions like temperature, humidity, oxygen, and light can trigger several reaction mechanisms that may lead to food quality degradation and reduction in shelf life (Taoukis et al., 1997; Rahman, 2007; Luning and Marcelis, 2009). Proper distribution and storage conditions would limit the rate of quality deterioration. Time between production and export could also affect the quality/safety of donated food, because, quality and safety of products gradually decreases with time (Rahman, 2007; Luning and Marcelis, 2009). Donated food is primarily not produced for food aid; it is commonly a surplus from donating countries and is often stored for a long time before being donated (Kripke, 2005; Barrett and Maxwell, 2006; Barrett and Maxwell, 2007; Levinsohn and McMillan, 2007). Origin of the food aid also affects the satisfaction of the food aid recipients due to pride of place and perceived differences in food safety and quality (Harou et al., 2013; Violette et al., 2013).

\section{Characteristics of donated food products}

Product characteristics refer to intrinsic sensitivity and type of packaging of donated food products. Sensitivity is the vulnerability of food quality attributes (i.e., nutritional value, safety and sensory properties) towards deterioration/decay. Intrinsic product sensitivity is an important factor in determining the final quality of donated food products; it depends mainly on intrinsic product conditions like $\mathrm{pH}$, water activity and composition of food (Rahman, 2007; Taub and Singh, 2010). It is assumed that the more vulnerable the product composition is towards nutritional loss, microbiological and organoleptic spoilage, the more negative it may affect the initial/basic product quality. At water activity $\left(\mathrm{a}_{\mathrm{w}}\right)$ values below 0.86 , most of the spoilage and pathogenic flora cannot survive, but the predominant spoilage flora consists of yeasts and moulds, some of which may grow even near 0.6 (Jay et al., 2008). Similarly, growth of microorganisms is affected by $\mathrm{pH}$ of the product; at low $(\mathrm{pH}<4.2)$ and high $\mathrm{pH}$ values $(p H>10)$ there is respectively no growth of acid sensitive microorganisms and enteric pathogens (Leistner and Gould, 2002; Jay et al., 2008). These product characteristics and presence of natural antimicrobial factors may prevent growth and survival of microorganisms (Leistner and Gould, 2002; Jay et al., 2008).

Type of packaging influences the quality and safety of donated food throughout the supply chain. Packaging prevents (biological and chemical) contamination of food products. In addition, some innovative packaging concepts (e.g. active and vacuum packaging) prevent growth of inherent micro-organisms ensuring that safe products reach the intended consumers. Packaging protects the form, shape and texture of the food inside, preventing the loss of flavours and odours and will often extend the products shelf life (World Packaging Organisation, 2009). Therefore, properly packaged products would protect from all agents of quality and safety deterioration. However, proper control of distribution conditions along the chain is also necessary.

\section{Characteristics of food control systems of donating countries}

Quality control systems in donating countries could also influence the quality of donated food. The national food control system is a group of elements (food laws and regulations, inspection services, laboratory services, management and administration, information, communication and training) organised and arranged in such a way that they can act as a whole to protect consumers' health (FAO/WHO, 2003; Hopper and Boutrif, 2007; Neeliah and Goburdhun, 2007). The nature, sophistication and results achieved by NFCS vary widely across countries (Hopper and Boutrif, 2007) and affect the control and monitoring of the food production system of the respective country. There could be differences in the way these systems are structured, operated and managed, the underlying principles, the institutions and groups involved and the resources available (Hopper and 
Boutrif, 2007). The availability of NFCS alone is not enough for proper control and assurance of quality and safety of food, but also depends on how well in practice control activities are executed (Hopper and Boutrif, 2007). However, the execution of different quality control activities depends on the availability of food legislation (Neeliah and Goburdhun, 2007). The governments should have responsibilities of establishing standards, legislation and enforcement programmes necessary to control food safety and quality (Mutukumira and Jukes, 2003; Hopper and Boutrif, 2007). The basic assumption is that an effective NFCS which oversees all food production activities results into compliance to the requirements guaranteeing the initial/basic quality of donated food.

Factors influencing the intermediate quality of donated food at point of receipt in the receiving countries

The intermediate quality refers to quality of donated food products determined at the point of entry or receipt in the receiving countries. The intermediate quality depends on how well the NFCS of receiving countries are organised and how well food control activities (inspection and analysis) in practice are executed; because poor control would most probably result in acceptance or rejection of food lots in a wrong way. The factors influencing the execution of these control activities which in turn could affect the intermediate quality of donated food include food legislation, infrastructure and resources as well as management and administration of the NFCS of the receiving countries. According to (Hopper and Boutrif, 2007) the capacity of a NFCS corresponds to its ability to perform appropriate functions effectively and sustainably in order to provide safe and quality food for both domestic consumption and export. Therefore, effective NFCS in the receiving countries enables better execution of quality control activities which determine the accepted quality level of donated food.

Food control refers to a mandatory regulatory activity (like inspection and analysis) enforced by the national/local authorities to provide consumer protection and ensure that all food during production, handling, storage, processing and distribution are safe, wholesome and fit for human consumption, conform to safety and quality requirements and are honestly and accurately labelled as prescribed by the law (Hopper and Boutrif, 2007). As for the food donating countries, effective NFCSs are also important for the receiving countries because, they contribute to increasing food quality and safety by reducing losses, adulteration and contamination, and the risk of foodborne diseases as well as control of food products for export and import (Neeliah and Goburdhun, 2007).

\section{Management or administration of national food control system}

Proper management and administration of NFCS supports the execution of control activities at receipt of donated food products. Management and administration are important elements of NFCS that organise control activities and operational coordination, which prevent dangerous or substandard food from reaching consumers (Neeliah and Goburdhun, 2007; Neeliah et al., 2009). Administrative procedures, operational coordination, and national food control strategy are regarded as influencing factors of management and administration of NFCs (FAO/WHO, 2003). Therefore, to get insights in the management and administration activities within the NFCS, operational coordination, national food control strategy, and communication and information availability were selected as the key factors.

Because most NFCSs are fragmented and shared within different ministries; effective linkages/coordination between food inspection service, laboratory analysts and the top management as well as between ministries and institutions involved in food control will reduce overlap of responsibilities, duplication of efforts and conflict of interests (FAO/WHO, 2003, 2004; Hopper and Boutrif, 2007). For a country to develop an integrated, coherent, and effective system, a national food control strategy is a pre-requisite. The national food control strategy determines areas of priority for action to ensure proper consumer protection, like introduction of HACCP-based programs along the food chain (Whitehead, 1995; FAO/WHO, 2003; Hopper and Boutrif, 2007). Also, communication and information supply across the system continuum is a prerequisite for its effectiveness (FAO/WHO, 2003). Proper communication and information supply indicates that all policies and quality/safety related matters are effectively and timely communicated (FAO/WHO, 2003; Mutukumira and Jukes, 2003) facilitating the decision making process by the personnel on quality and safety aspects of the products.

\section{Infrastructure and resources of national food control system}

The infrastructure and resources of the national food control system determine how well the control activities are executed; they include financial and human resources, facilities for inspection, sampling and analysis (Anyanwu and Jukes, 1990; Mutukumira and Jukes, 2003; Neeliah and Goburdhun, 2007). Good infrastructure and resources support the execution of food control activities. Proper inspection, sampling and analytical methods may reduce the risk of accepting poor quality lot or rejection of good quality lot. To assess the infrastructure and resources of the NFCS we have 
selected; financial support, laboratory facilities, the operational procedures, and quality of the personnel as the major influencing factors.

Lack of financial support is an underlying factor which limits the establishment of effective systems in most developing countries (FAO/WHO, 2004; Neeliah and Goburdhun, 2007). Adequate financial support for personnel training and infrastructure improvement (e.g. equipment, standards, and chemical reagents) indicates that the food control activities are effectively executed (FAO/WHO, 2003; Neeliah and Goburdhun, 2007). Also, laboratories should have adequate facilities for physical, microbiological and chemical analyses (Mutukumira and Jukes, 2003; Neeliah and Goburdhun, 2007; Nguz, 2007). Lack of laboratory facilities may lead to ineffective NFCS, which performs basic analyses or relies on visual inspections and leave out very important food safety analyses such as pathogens, chemical (pesticide and veterinary drugs) residues as well as mycotoxins.

The operational procedures in inspection, sampling and analysis determine how accuracy sampling and analysis are conducted in practice. Scientifically based and validated inspection and sampling procedures for imported food products at the ports and/ or all points of entry stipulate that lots of products are properly inspected and representative samples are drawn, which produce accurate and reliable analytical results. The nature and frequency of inspection, sampling and analysis of imported foods, however, they should be based on the risk of human health and safety presented by the product, the origin of food aid and country's history of conformance (Codex Alimentarius Commission, 2003). Furthermore, laboratories need to be accredited to guarantee their competence and validity of the data produced (Varzakas et al., 2006). The execution of NFCS activities also depends on the qualities of the workforce (i.e. education, competence and experience of laboratory analysts and food inspectors). Availability of adequate, well-trained/educated, competent and experienced personnel indicates that product inspections and analyses will be performed effectively to ensure consumer protection (Hopper and Boutrif, 2007). Besides, the reputation and integrity of the NFCS depend on the competence and skills of the workforce (Anyanwu and Jukes, 1990; Whitehead, 1995; FAO/WHO, 2003).

\section{Food legislation}

Food legislation is a complete body of legal texts (laws, regulations and standards) that establishes broad principles for food control in a country. Also, it governs all aspects of the production, handling, marketing and trade of food as a means to protect consumers against unsafe food and fraudulent practices (Hopper and Boutrif, 2007; Meulen et al., 2008). The primary purposes of food legislation are to protect the health of consumer, to protect the consumer from fraud and to ensure the essential quality and wholesomeness of food (Whitehead, 1995; Käferstein, 2003; Neeliah et al., 2009). It provides basis and authority for an operating NFCS (Codex Alimentarius Commission, 2003; Hopper and Boutrif, 2007; Neeliah and Goburdhun, 2007). To analyse the food legislation; food laws and regulations, and enforcement and monitoring system of food laws were used as major influencing factors.

Food laws and regulations are essential components for an effective and powerful NFCS. The food laws must have all terms clearly defined including the main provisions, main offences, defences, penalties, duties and powers, inspection and analytical procedures, enforcement procedures and repeals (Whitehead, 1995; Neeliah and Goburdhun, 2007). Food regulations should cover general definitions, compositional standards, labelling, sampling inspection, hygienic specification, procedures for food handling, processing, storage, shipping, sale and contamination levels (Whitehead, 1995).

An effective enforcement and monitoring system is highly needed to ensure compliance of food laws and regulations (Käferstein, 2003; Hopper and Boutrif, 2007). An ideal NFCS should among others include an effective mechanism of enforcing mandatory requirements (FAO/WHO, 2004; Hopper and Boutrif, 2007). In addition, it should provide the competent authority with the power to accept, reject, detain, destroy, order to reprocess, return to country of export, designate as non-food use, apply risk-based sampling plan, and recall consignments following importation (Codex Alimentarius Commission, 2003). An efficient enforcement and monitoring system of food laws and regulations ensures proper execution of food control activities (Neeliah et al., 2009).

\section{Factors influencing the final quality of donated food during distribution in receiving countries}

Final quality of donated food refers to quality of products determined at the final distribution point(s). The final quality of donated food during distribution could be influenced by the product characteristics (see section 4.1.2), complexity of the supply chain, nature of the distribution infrastructure, and qualities of the workforce involved in the distribution. It is reported that deterioration in quality of donated food often takes place after the food has reached the recipient countries; because of poor storage and distribution conditions prevailing in crisis situations (Wareing et al., 1993). Furthermore, humanitarian operations may be hindered by administrative and logistical bottlenecks because of poor physical infrastructure in the aid-receiving regions and the multiplicity of agencies and government institutions, and are often in conflict zones, thus hampering efficient delivery and distribution of relief cargoes to the needy 
150 Afr. J. Food Sci. Technol.

(Özdamar et al., 2004; Oloruntoba and Gray R., 2006; De Angelis et al., 2007). Political instability, in-country infrastructure and topography are the major factors affecting the donated food transportation systems in the receiving countries (Özdamar et al., 2004; De Angelis et al., 2007; Beamon and Balcik, 2008).

\section{The complexity of the supply chain in receiving countries}

In the receiving countries, complexity of the supply chains is amongst the factors that could affect the ultimate quality of donated food. Unlike business supply chains, humanitarian aid supply chains are often shorter and unstable existence, and lack planning, which result into inefficiencies like congestion due to unplanned deliveries (Oloruntoba and Gray R., 2006). Moreover, the complex nature of the distribution system and the wide range of daily and seasonal temperatures impose significant stresses on the products that may need proper monitoring (Taub and Singh, 2010). Therefore, distance and accessibility, transport and storage capacity, and number of nodes, links and delivery destinations to be served are used as the key factors to assess complexity of the donated food supply chains in the receiving countries.

Distance and accessibility of the chain could affect the final quality of donated food in diverse ways. Distance determines how long the products would stay on board and to what extent the products are exposed to harsh conditions aggravating quality deterioration processes. In short distance chains, the products could take relatively shorter time to reach the final destination; hence, little monitoring and handling activities are required as compared to long distance chains. However, during the emergencies, relief operations often have to be carried out in an environment with destabilized infrastructures ranging from a lack of electricity supplies to limited transport infrastructure (Kovács and Spens, 2007). Moreover, poor accessibility, as in isolated mountainous villages and communities; the final destination may not be accessible via trucks, trains, barges and aircraft.

In such a situation, a drop-off point is normally identified where food aid is delivered using regular means of transport (like trucks/trains), the recipient communities then organise and mobilise local resources (e.g. draft animals or manually) to collect the food commodities and deliver the food aid to the final distribution point (Stevenson, 1995; Hale, 1999; Rancourt et al., 2015), if not properly controlled, this operation could expose the products to excessive handling and cross contamination.

The transport and storage capacity determines the range of monitoring and control activities which in turn may affect the ultimate quality of donated food. The storage capacity depends on transportation capacity and the rate of dispatch. If commodities are received and dispatched through the node at a fairly constant rate; then large quantities of stock will not accumulate and storage requirements will be minimal (Hale, 1999). Similarly, big transportation capacity eliminates or shortens the interim storage time and enables the products to reach the final destinations in relatively shorter period (i.e. eliminates excessive handling or interim storage) that assures high ultimate quality of donated food. However, food aid receiving regions are characterised by lack of storage facilities, if food have to be stored before distribution very rudimentary stores could be used or food can just be heaped on the ground and covered with tarpaulins. These processes may aggravate food spoilage conditions influencing quality of the food aid.

Complexity of the supply chain is also determined by the number of nodes, links, and delivery destinations (Hale, 1999; Özdamar et al., 2004) which could affect the ultimate quality of donated food products. The supply chain is composed of two basic components; nodes and links. Nodes are points in the network where commodities are received, stored, and dispatched, whereas links are the transportation corridors connecting nodes on which the commodities will move, like roads, rail tracks, water ways, and air corridors (Hale, 1999). At nodes, commodities could be received on one mode of transport, for example, trucks, and transferred to another mode of transport like trains or boats. Also, at nodes, commodities may be received and issued using the same mode of transport, but with different characteristics; for instance, received on large capacity trucks and dispatched on smaller trucks due to poorer road conditions or the need to deliver to multiple destinations (Hale, 1999; Stewart, 2003). This would also need additional secondary and tertiary warehouses to temporarily store the products (Stewart, 2003). Combination of all these activities may expose the products to excessive handling and (cross) contamination, which negatively affect the final quality of donated food. It is reported that each loading and unloading operation at a food transfer point or interim storage facility introduces a thermal stress (Taub and Singh, 2010) and improper handling could result into cross contamination affecting quality of products.

\section{Nature of the local distribution infrastructure}

The final quality of donated food could be also influenced by the nature of the local infrastructure of the receiving countries. It is assumed that good and sustainable distribution infrastructure of the receiving countries would reduce delays, offloading and product contamination; thus, limiting product spoilage and guaranteeing consistent quality and safety of donated food products along the distribution chain. To assess the nature of the local distribution infrastructure; type of transport, the road 
conditions, and the number and capacity of bridges/ferries are used as the key factors.

Type of transport refers to the mode of transport (e.g. water, air and/or land) and vehicle or vessel (e.g. ship, cargo flights, train) used to carry the products. Fast transportation method like air transport is expected to reduce transportation time, which may reduce exposure time to harsh conditions. However, other transportation methods like road transport to the final delivery and interim storage of donated food would be needed. Although, air drop is a major method used in emergencies and in areas characterized by tribal wars and political instability (Kovács and Spens, 2007; Beamon and Balcik, 2008); where control is limited it may negatively affect quality of products because of excessive vibrations and impacts, which could break the package/product and introduce physical contaminants. If not managed properly, water transport could expose the products to water contamination which may induce microbial deterioration and accelerate rancidity of fats and fat-soluble vitamins such as vitamin A (Rahman, 2007) and may compromise quality, safety and shelfstability of the products (Bourlieu et al., 2008). Despite the fact that rail transport is a slow process, it carries large quantities of food, which reduces excessive product handling.

Also road conditions may influence quality of donated food due to unnecessary delays, excessive handling and contamination. Most receiving countries and regions in need of food aid could be at remote areas with seasonal roads (e.g. gravel roads) which are in poor conditions to allow timely delivery of products and could cause product spoilage if not properly monitored. The capacity of bridges or ferries along the distribution chain could delay or prevent transportation of food aid depending on size of the cargo. Smaller capacity bridges allow transport of light-weight cargoes; which may lead to heavy-weight trucks being offloaded. Depending on the size of the cargo and subsequent transportation capacity; temporary storage might be required, which could expose the products to contamination and other adverse reactions (Stewart, 2003).

\section{Qualities of the personnel in the distribution chain in the receiving countries}

Qualities of the personnel involved in the distribution chain may also influence the quality of donated food. Education, experience and competence of the personnel involved in the product distribution chain are selected as major factors to assess qualities of the workforce. If people are well-trained on the risks that might be caused by poor product handling, they could improve product handling or distribution practices (Anyanwu and Jukes, 1991; FAO/WHO, 2003; Barrett and Maxwell, 2006). The leading causes of food deterioration and spoilage are improper distribution and excessive handling practices that could induce mechanical damage and microbiological contamination (Rahman, 2007). Adequate, well-trained (community based food aid targeting and distribution), experienced and competent personnel along the distribution chain would improve the efficiency of the distribution chain and enables timely distribution and preventing excessive handling (interim and inadequate storage) or poor distribution practices. This could also prevent hiring of temporary workers, who are often non-skilled and inexperienced with food distribution during the emergencies.

\section{The analytical framework of donated food supply chains}

The theoretical framework is a result of comprehensive analysis of literature and discussion with experts on: food aid and food aid supply chains, food safety, food quality, food security, food analysis, food control systems and disaster management. The theoretical framework (Figure 1) shows the key-risk factors that may have impacts on the quality and safety of donated food along the food aid supply chains. It is divided into three distinct parts: 1) key-risk factors influencing the initial/basic quality and safety of donated food in the donating countries or country of purchase, 2) key-risk factors impacting the intermediate quality and safety of donated food at receipt in the receiving countries, and 3) key-risk factors influencing final quality/safety of donated food during distribution in the receiving countries.

There are three different grids assessing the impacts of critical factors influencing initial/basic quality of donated food in the donating countries (Table 1), intermediate quality of donated food at receipt (Table 2) and final quality during distribution in the receiving countries (Table 3). For each factor, a description of how it may impact quality of donated food at all stages of the supply chain is given. Also the assessment grids are typified into two situations; low-risk and high-risk. Low-risk corresponds to a situation whereby certain factors could not result into poor product safety/quality. The factors have no/restricted negative impacts on quality and safety of products along the food aid supply chain (i.e. in donating countries/country of purchase, at receipt and during distribution in the receiving countries). High-risk refers to factors that can have negative impacts on the quality and safety of donated food along the chain.

\section{Factors influencing the initial quality of food products in the donating countries}

Table 1 displays a grid to judge the impacts of key-risk factors on quality and safety of food products in the donating countries/country of purchase, and the 

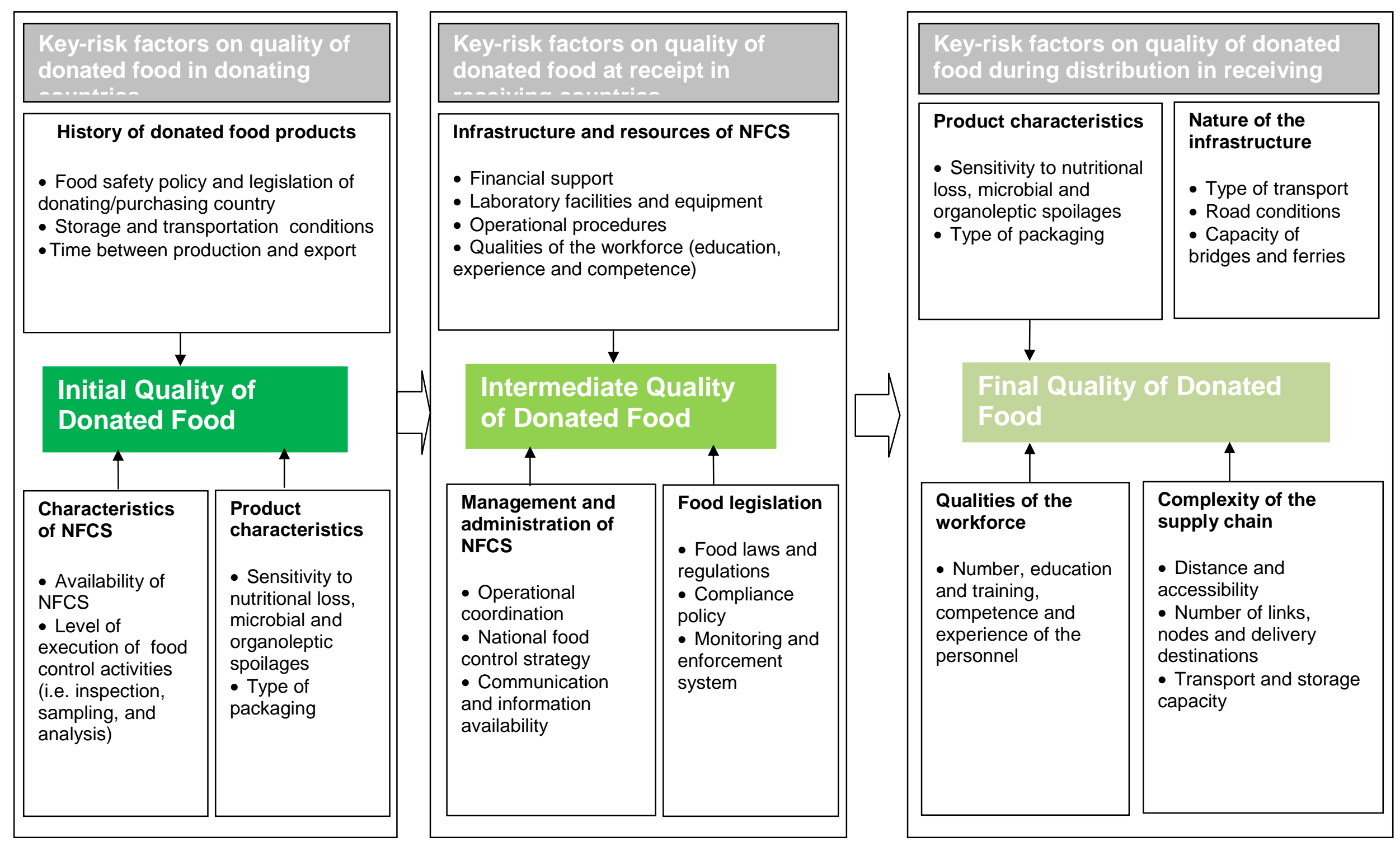

Figure 1. Theoretical framework of key-risk factors on quality and safety of donated food along the supply chain 
Table 1. Grid to judge impacts of key-risk factors on initial quality of donated food in the donating countries

\begin{tabular}{|c|c|c|c|}
\hline Indicators & Assumed mechanisms & Low-risk situation & High-risk situation \\
\hline \multicolumn{4}{|c|}{ History of donated food } \\
\hline $\begin{array}{l}\text { Food safety policy } \\
\text { and food legislation } \\
\text { of donating country }\end{array}$ & $\begin{array}{l}\text { If donating country or country of purchase has } \\
\text { effective food safety policy and food legislation (food } \\
\text { laws and regulations), the inadequacies in safety and } \\
\text { quality parameters of donated products will be } \\
\text { reduced }\end{array}$ & $\begin{array}{l}\text { Food products come/purchased from a country } \\
\text { with food safety policy, adequate and effective } \\
\text { food laws and regulations }\end{array}$ & $\begin{array}{l}\text { Food products come/purchased from a } \\
\text { country without food safety policy and } \\
\text { specific food laws and regulations }\end{array}$ \\
\hline $\begin{array}{l}\text { Storage } \\
\text { transportation } \\
\text { conditions }\end{array}$ & $\begin{array}{l}\text { If food products are transported and stored in } \\
\text { appropriate conditions, the rate of quality } \\
\text { deterioration will be significantly reduced and the } \\
\text { original quality maintained }\end{array}$ & $\begin{array}{l}\text { Products are stored and transported in } \\
\text { appropriate conditions, and separated according } \\
\text { to their characteristics and packaging }\end{array}$ & $\begin{array}{l}\text { Products are stored and transported in } \\
\text { ambient conditions; no proper monitoring } \\
\text { of storage and transportation conditions }\end{array}$ \\
\hline $\begin{array}{lr}\text { Time } & \text { between } \\
\text { production } & \text { and } \\
\text { export } & \end{array}$ & $\begin{array}{l}\text { If the time between production and export is very } \\
\text { short, products will be stored for very short time } \\
\text { limiting the rate of quality deterioration; hence high } \\
\text { initial quality }\end{array}$ & $\begin{array}{l}\text { Products take very short time from production to } \\
\text { export; storage conditions are properly controlled } \\
\text { and monitored }\end{array}$ & $\begin{array}{l}\text { Products take long time between } \\
\text { production and export; no proper control } \\
\text { or monitoring of storage conditions }\end{array}$ \\
\hline \multicolumn{4}{|c|}{ Product characteristics } \\
\hline $\begin{array}{l}\text { Sensitivity } \\
\text { nutritional } \\
\text { microbial los } \\
\text { organoleptic } \\
\text { spoilages }\end{array}$ & $\begin{array}{l}\text { The more sensitive the product is towards } \\
\text { respectively loss of nutritional value, microbial and or } \\
\text { organoleptic spoilage the more negative it affects the } \\
\text { initial quality }\end{array}$ & $\begin{array}{l}\text { Most products are insensitive to loss of } \\
\text { nutritional value, microbial and organoleptic } \\
\text { spoilages and they are properly packaged }\end{array}$ & $\begin{array}{l}\text { Most products are very sensitive to loss of } \\
\text { nutritional value, microbial and } \\
\text { organoleptic spoilages; no proper } \\
\text { packaging }\end{array}$ \\
\hline Type of packaging & $\begin{array}{l}\text { If donated food products are properly packaged } \\
\text { (package design and conditions) the rate of } \\
\text { deterioration and spoilage of products would be } \\
\text { reduced }\end{array}$ & $\begin{array}{l}\text { Food products are properly packaged to prevent } \\
\text { contamination and growth of micro-organisms } \\
\text { including pathogens }\end{array}$ & $\begin{array}{l}\text { Food products are not properly packaged; } \\
\text { cross contamination and growth of micro- } \\
\text { organisms including pathogens are likely }\end{array}$ \\
\hline \multicolumn{4}{|c|}{ Characteristics of national food control systems (NFCS) of donating countries } \\
\hline $\begin{array}{l}\text { Availability } \\
\text { effective NFCS }\end{array}$ & $\begin{array}{l}\text { Effective NFCS (i.e., inspection, sampling, } \\
\text { surveillance/monitoring of food production system) } \\
\text { ensures that products are produced, processed, } \\
\text { stored and transported in appropriate conditions }\end{array}$ & $\begin{array}{l}\text { The country has an effective NFCS which } \\
\text { oversees all food production processes including } \\
\text { food import and export }\end{array}$ & $\begin{array}{l}\text { The country has no operational NFCS in } \\
\text { place }\end{array}$ \\
\hline $\begin{array}{l}\text { Execution of food } \\
\text { control activities }\end{array}$ & $\begin{array}{l}\text { High level of execution of food control activities } \\
\text { (inspection, sampling, analysis, monitoring) } \\
\text { guarantees production and donation of high quality } \\
\text { products }\end{array}$ & $\begin{array}{l}\text { High level of execution of food control activities } \\
\text { in production and procurement system (i.e. } \\
\text { preventive measures are established along the } \\
\text { production chain) }\end{array}$ & $\begin{array}{l}\text { No strict control on the execution of food } \\
\text { control activities }\end{array}$ \\
\hline
\end{tabular}

mechanism through which the initial/basic quality is affected. The assumed mechanism for the history of donated food products is that if donating countries have effective food safety policies and food legislation; better quality products will be produced and/ or purchased or provided. A lowrisk situation refers to when the food products are imported/purchased from a country with effective food safety policy and food laws and regulations; whereas a high-risk situation is foreseen when the food products are imported from a country without food safety policy and specific food laws and regulations to effectively control even her production for the local supplies/domestic market. Food laws and regulations identify the 
Table 2. Grid to judge impacts of key-risk factors on intermediate quality of donated food at receipt in the receiving countries

\section{\begin{tabular}{lll}
\hline Indicators Assumed mechanisms $\quad$ Low-risk situation \\
\hline The National food control systems (NFCS) infrastructure and resources of food aid receiving countries
\end{tabular}}

Financial support Availability of adequate financial support for training. There is adequate funds for all equipment and improvement of NFCS infrastructure; necessary activities to be carried out contributes to effective execution of food control in the NFCS activities at receipt

Laboratory facilities

Availability of adequate facilities and sophisticated equipment for analysis (physical, microbiological and chemical hazards) indicates that all potential hazards are effectively analysed, hence, high quality products are accepted

Operational procedures: (inspection sampling,

laboratory analysis)

Qualities of the workforce

(number,

education competence) pesticides and other contaminants

Use of statistically based sampling plan significantly reduces the possibility of accepting poor quality food and products

Use of standardised methods (international or national) of analysis produces accurate and reliable analytical results, which prevent rejection or acceptance of a batch of products in a wrong way If the quality attributes of donated food are thoroughly analysed; products of good quality will be accepted

If formal and internationally acknowledged procedures for inspection and analysis are used, proper sampling and analysis will be carried out leading to accurate analytical results and acceptance of good quality products

Proper storage and transport of analytical sample prevent sample deterioration or contamination; which leads to accurate and reliable analytical results at $\leq 4^{\circ} \mathrm{C}$

sampling plans; statistics used to frequency and rejection criteria and validated methods) carried out nternational (validated) guidelines and are well documented with food analysis
There are both basic and sophisticated equipment for all necessary analyses including pathogens, mycotoxins, allergens,

Samples are hygienically stored or transported according to their specific conditions, temperature is maintained determine appropriate sample size

All methods are standardised

according to national guidelines and international protocols (i.e., accredited

Physical parameters, toxins, Food analysis is mainly on few attributes microbiological, chemical (pesticides, like flavour, smell, colour, and fill rate which mycotoxins) and allergen analyses are not important with respect to quality and (both qualitative and quantitative) are

All procedures are based on

are no formal and internationally acknowledged procedures for inspection and analysis; all procedures are in-house

No specific storage or transportation conditions; all samples are stored or transported in ambient conditions

The NFC has adequate number of The NFC has limited number of well trained well trained, competent and and competent personnel; majority have experienced ( $>5$ years) personnel general knowledge on food quality and

restricted experience of $<1$ year 
Table 2 Continues

\section{Management and administration of NFCS}

Operational

coordination

National Proper coordination within the NFCS (inspection,
laboratory, surveillance and top management) leads to an efficient system

control strategy

ood The national food control strategy results into development of an integrated, coherent, effective and dynamic NFCS, and defines areas of priority for action, which ensure and defines areas

Communication Good communication and information system ensures that and information all policies, administrative issues and quality/safety related availability matters are accurately communicated, which support the execution of food control activities

Food legislation

Food laws and Adequate food laws and regulations providing the NFCS regulations

Compliance policy mandate/authority to prevent food safe and transparency in decision making with respect to product compliance matters

Monitoring and Proper monitoring and enforcement of food laws and

enforcement

regulations ensure proper implementation and effectiveness
Proper coordination between different A few departments collaborate in some aspects departments/other institutions involved in but not always. NFCS involves multiple food control. The NFCS is a single unified agencies/institutions without clear description of agency/entity

The national food control strategy covers The national food control strategy is not explicitly the whole chain (from farm to table); it is incorporated and implemented in our food control used as a basis and direction for operations execution of food control activities

The NFCS has a specific Quality Information system is not specific for quality Information Management (QIM), which is control, however, some information sources are accessible to all people to support the suitable for proper decision making. The system execution of food control activities and it is is only accessible to authorized people and is kept up-to-date

kept-up-to date on ad-hoc basis

There are adequate, effective and updated specific food laws and regulations

Availability of compliance policy which gives basis for decision making with respect to food safety and quality

There are no food laws and regulations or food laws and regulations are general, fragmented and out-dated

There is no compliance policy; decision to accept or reject a batch of product comes from the personnel

Availability of effective monitoring and Not always monitoring and enforcement of food enforcement procedures of food laws and laws and regulations are carried out regulations requirements of food quality standards, good practices (Good Agricultural practices (GAP); Good manufacturing practices (GMP); Good hygienic practices (GHP) and Good Distribution practices (GDP)), record keeping, product testing and food handling, preparation and service (Whitehead, 1995; Neeliah et al., 2009). With respect to the storage and transportation conditions in donating countries it is assumed that if food is transported and or stored in appropriate conditions (e.g. temperature, humidity/moisture), the rate of quality deterioration will be significantly reduced and original quality consistently maintained. A low-risk situation is therefore, typified by food products being stored and transported in appropriate conditions and separated according to their characteristics and packaging. A high-risk situation is characterised by products stored and transported in ambient conditions, not protected and no proper monitoring of storage/transportation conditions. On the other hand, time between production and export may affect products quality depending on the storage conditions. However, short-time between production and export indicates that food products are stored for relatively short time which limits the rate of quality deterioration. In this view, low-risk situation is anticipated when the time between production and export is very short (i.e. less than a year, depending on the products), and high-risk situation is expected if the time span between production/processing and export is very long (i.e. years).

The more sensitive the product is towards respectively loss of nutritional value, microbial and or organoleptic spoilage the more negative it affects the initial quality. Low-risk situation is expected when products are insensitive towards loss of nutritional value, microbiological and organoleptic spoilages; whereas high-risk situation is indicated by sensitivity of NFCS of the donating countries/countries of purchase play a 
Table 3. Grid to judge impacts of key-risk factors on final quality of donated food during distribution to the recipients

\begin{tabular}{|c|c|c|c|}
\hline Indicators & Assumed mechanism & Low-risk situation & High-risk situation \\
\hline \multicolumn{4}{|c|}{ Complexity of the food aid supply chain } \\
\hline $\begin{array}{ll}\text { Distance } & \text { and } \\
\text { accessibility } & \end{array}$ & $\begin{array}{l}\text { Short distance and easily accessible chains reduce the rate of } \\
\text { exposure of products to harsh conditions, which positively } \\
\text { contributes to final quality }\end{array}$ & $\begin{array}{l}\text { Short distance chains accessible under } \\
\text { all weather (rain and dry season) }\end{array}$ & $\begin{array}{l}\text { Long distant chains accessible only } \\
\text { during the dry seasons }\end{array}$ \\
\hline $\begin{array}{l}\text { Number of links, } \\
\text { nodes and delivery } \\
\text { destinations }\end{array}$ & $\begin{array}{l}\text { Several links, nodes and delivery destinations result into } \\
\text { offloading, interim storage and re-loading which increases the } \\
\text { rate of exposure of the products to harsh conditions or } \\
\text { contamination }\end{array}$ & $\begin{array}{l}\text { Chain with } 1-2 \text { nodes or delivery } \\
\text { destinations; which does not need any } \\
\text { reloading or interim storage }\end{array}$ & $\begin{array}{l}\text { Chain with }>2 \text { nodes and delivery } \\
\text { destinations; which need reloading and } \\
\text { interim storage }\end{array}$ \\
\hline $\begin{array}{l}\text { Transport and } \\
\text { storage capacity }\end{array}$ & $\begin{array}{l}\text { If large quantities of food products are transported per given } \\
\text { period, there will be minimal storage requirements which reduce } \\
\text { excessive handling }\end{array}$ & $\begin{array}{l}\text { All products are transported and } \\
\text { distributed at once; there is no further } \\
\text { storage }\end{array}$ & $\begin{array}{l}\text { Products are transported and or } \\
\text { distributed in instalments, further storage } \\
\text { is necessary }\end{array}$ \\
\hline \multicolumn{4}{|c|}{ Nature of infrastructure } \\
\hline $\begin{array}{l}\text { Type of transport } \\
\text { (motor vehicle, train, } \\
\text { ship or airplanes) }\end{array}$ & $\begin{array}{l}\text { The type of transport dictates the speed of transportation process. } \\
\text { The faster the transportation processes the lesser the time the } \\
\text { products exposed to harsh conditions }\end{array}$ & $\begin{array}{l}\text { Airplanes, cars, ships and trains are all } \\
\text { used for transportation purposes; take } \\
\text { less than a week to reach the final } \\
\text { destination }\end{array}$ & $\begin{array}{l}\text { The main types of transport used are } \\
\text { carts pulled by draft animals and } \\
\text { manually; take more than a week to the } \\
\text { destination }\end{array}$ \\
\hline Road conditions & $\begin{array}{l}\text { If the roads can induce mechanical damage and dust } \\
\text { contamination to transported products; it will affect the quality of } \\
\text { food products }\end{array}$ & $\begin{array}{l}\text { Roads are in good condition (e.g. } \\
\text { tarmacked roads) which reduce the rate } \\
\text { of mechanical damage and dust } \\
\text { contamination }\end{array}$ & $\begin{array}{l}\text { Roads are in poorer conditions; products } \\
\text { are often mechanically damaged and } \\
\text { contaminated }\end{array}$ \\
\hline $\begin{array}{l}\text { Capacity of bridges } \\
\text { or ferries }\end{array}$ & $\begin{array}{l}\text { Small capacity bridges cause offloading of large cargos to } \\
\text { required weight, which exposes the products to excessive } \\
\text { handling affecting the final quality }\end{array}$ & $\begin{array}{l}\text { Large capacity bridges/ferries which } \\
\text { prevent offloading of cargoes }\end{array}$ & $\begin{array}{l}\text { Small capacity bridges/ferries which } \\
\text { sometimes need offloading of heavy } \\
\text { weighted cargoes }\end{array}$ \\
\hline \multicolumn{4}{|c|}{ Qualities of the workforce } \\
\hline $\begin{array}{l}\text { Education and } \\
\text { training, competence, } \\
\text { experience and } \\
\text { number of personnel }\end{array}$ & $\begin{array}{l}\text { Adequate, well trained and educated, competent and experienced } \\
\text { personnel with proper food handling will reduce unnecessary } \\
\text { delays and contamination of products }\end{array}$ & $\begin{array}{l}\text { Adequate, well trained, competent and } \\
\text { experienced personnel with food } \\
\text { distribution during the emergencies }\end{array}$ & $\begin{array}{l}\text { Limited number, not well trained } \\
\text { personnel with restricted experience on } \\
\text { food distribution during the emergencies }\end{array}$ \\
\hline
\end{tabular}

significant role on the initial quality of donated food. The assumed mechanism is that effective NFCS (i.e., inspection, sampling, surveillance and monitoring of production system) ensures that products are produced, processed, stored and transported in appropriate ways. A low-risk situation is exemplified by availability of effective NFCS, and a high-risk situation is expected when there is no operational control system in place. Lastly, the way execution of food control activities are carried out affects quality of food. High level of execution of food control activities guarantees production and donation of good quality products. A low-risk situation corresponds to high level of execution of food control activities in production and procurement of donated food, whereas, a high-risk situation refers to when there is no strict control on the execution of food control activities.

Factors influencing the quality of donated food at point of receipt in the receiving countries

A grid to judge the impacts of factors influencing the quality of donated food at receipt is shown in 
Table 2. It is assumed that proper food control infrastructure and resources, proper management and administration, and effective food legislation result into proper execution of food control activities (e.g. inspection, sampling and analysis) at point of receipt in receiving countries. The key-factors used to assess the food control infrastructure include financial support, laboratory facilities, operational procedures and qualities of the NFCS workforce.

The assumed mechanism for the financial support is that availability of adequate financial support for training, equipment purchasing and improvement of the infrastructure; contributes to effective execution of control activities at receipt. A low-risk situation corresponds to availability of enough funds to carry-out all the necessary activities in the NFCS, while limited funds to properly execute control activities indicates a high-risk situation. The major cause of poor performance of NFCS is inadequate financial support, which leads to understaffing and ill-equipped laboratory facilities (Vytelingum, 2003; Hopper and Boutrif, 2007; Neeliah et al., 2009). The assumed mechanism for laboratory facilities is that availability of adequate facilities and sophisticated equipment for analysis of physical, microbiological and chemical hazards could result into effective analysis of all potential hazards; hence, high quality (safety) products are accepted. It is recommended that food samples should be properly tested to determine the identity and concentration of food contaminants, including microbial pathogens, hazardous chemicals, natural toxins, and harmful parasites (Nguz, 2007). Low-risk situation corresponds to availability of sophisticated equipment to analyse all hazards, whereas availability of basic equipment to exclusively carry out basic analyses (e.g. qualitative analyses) indicates a high-risk situation.

The assumed mechanism for operational procedures for inspection, sampling and laboratory analysis is that use of validated and/or internationally acknowledged procedures for inspection, sampling, and analysis will results into accurate analytical results preventing acceptance and/ or rejection of a batch of products in a wrong way. A low-risk situation is expected when all methods used are standardised according to the national guidelines and international protocols (i.e., accredited/validated methods); while high-risk situation is indicated by absence of formal and internationally acknowledged analytical procedures. Food control laboratories deal with very complex analytical problems, caused by product composition interferences; the problems could be overcome by use of the latest analytical instruments and sophisticated methods of analysis and techniques which are accurate and validated (FAO/WHO, 2003). In addition, internationally validated standard methods of analysis should be used for analysis of imported foods; and analysis should be conducted in official or accredited laboratories (Codex Alimentarius Commission, 2003).
With regards to qualities of the workforce, it is assumed that if the NFCS has limited number of qualified personnel or personnel with poor technical capability; they may focus on basic analyses and leave very important analyses for food quality/safety. Analytical staff having basic level of education and limited experience and competence cannot perform complex food analyses (Neeliah and Goburdhun, 2007; Nguz, 2007). Therefore, a low-risk situation is expected when there are adequate trained personnel (i.e. in food quality and safety), competent and experience of at least five years, while a poor situation is indicated by majority of personnel with general knowledge, restricted experience ( $<1$ year) and competence. Use of non-professional personnel with very limited experience could result into inefficient operation/execution of food control activities (Neeliah and Goburdhun, 2007; Nguz, 2007; Neeliah et al., 2009).

For the management and administration of NFCS; operational coordination, national food control strategy, communication and information supply are selected as major factors. With respect to operational coordination it is assumed that proper coordination within the NFCS (e.g. inspection, laboratory, top management) results into an efficient system. A low-risk situation corresponds to single and unified NFC characterized by proper coordination between different departments and other stakeholders involved in food control (Neeliah et al., 2009). A single unified agency approach results into uniform application of protective measures, ability to act quickly to protect consumers, improved cost efficiency and more effective use of resources and expertise, harmonization of food standards and capacity to quickly respond to emerging challenges and demands of both domestic and international markets (FAO/WHO, 2003). High-risk situation is likely when NFCS is a combination of multiple agencies (i.e. non-integrated) responsible for food control, which may complicate coordination. Multiple agencies lead to problems like duplication of regulatory activity, increased bureaucracy, fragmentation and lack of coordination between different bodies involved in food policy, monitoring and control of food safety (FAO/WHO, 2003; Hopper and Boutrif, 2007; Neeliah et al., 2009).

With regards to national food control strategy, it is assumed that national strategy enables a country to develop an integrated, coherent, effective and dynamic NFCS and defines areas of priority for action, which ensures consumer protection (FAO/WHO, 2003; Hopper and Boutrif, 2007). A low-risk situation refers to existence of national food control strategy on food quality and safety that covers the whole chain, which is used as a basis and direction for food control activities. A high-risk situation is anticipated when the national food control strategy is not explicitly incorporated and implemented in the system. Also it is assumed that good communication and information supply improves performance of the system; because food safety policies, administrative 
issues, quality and safety related matters are accurately and timely communicated.

Food laws and regulations, compliance policy, and monitoring and enforcement system are the major factors used to assess the national food legislation. The assumed mechanism for food laws and regulations is that adequate and effective food laws and regulations provide the NFCS with clear mandate and authority to prevent food safety problems. A low-risk situation corresponds to availability of adequate, effective and up-to-date specific food laws and regulations whereas, a high-risk situation is indicated by existence of fragmented and outdated food laws and regulations. The enforcement of fragmented and large number of food laws and regulations accompanied by mandatory limits/tolerances and standards will require many resources, which are not available in most developing countries (Vytelingum, 2003). Compliance policy leads to uniform application of food legislation, transparency in decisions, and provision of specific instructions to the workforce as well as general guidance to compliance matters. A low-risk situation is indicated by availability of compliance policy, whereas, high-risk situation corresponds to lack of compliance policy. Proper monitoring and enforcement of food laws and regulations ensure their proper implementation and effectiveness. A low-risk situation is expected when there are effective monitoring and enforcement procedures of food laws and regulations, whereas high-risk situation is reflected when monitoring and enforcement are not always possible. If several institutions and food control authorities are involved in the enforcement of food laws and regulations accompanied by lack of uniform procedures could result into inadequate enforcement (Neeliah and Goburdhun, 2007).

\section{Factors influencing quality of donated food during distribution in receiving countries}

Table 3 details a grid to judge the impacts of key-factors influencing the final quality of donated food during distribution in the receiving countries. It is assumed that food sensitivity (as indicated in Table 1), complexity of the supply chain, nature of infrastructure and qualities of the workforce determine the quality of food products during distribution. Three factors are used to assess the complexity of the food aid supply chain: distance and accessibility of the chain, number of links, nodes and delivery destinations, and the transport and storage capacity. With regards to distance and accessibility, it is assumed that short distance and easily accessible chains prevent exposure of the products to harsh handling conditions (e.g. sun blazing, mechanical damage and moisture/humidity) for long periods; which consistently maintain quality of donated food. A better situation is expected when the supply chain has short distance and accessibility is under all weather (rain and dry season).
This would not only improve accessibility, but also reduce turnaround time, ensure better utilisation of trucking capacities, minimise the opening of additional secondary and tertiary warehouses (thereby reducing the need to rent additional warehouses and staff), reduce the risks of losses associated with food deterioration by minimising storage periods in small warehouses (especially for maize flour and other milled produce), and minimise the hiring of expensive multiple-traction trucks (Stewart, 2003). A high-risk situation is characterized by long distance chains which are partly accessible during the dry seasons (i.e. the main transport is by horses or carts pulled by draft animals). It is assumed that several links, nodes and delivery destinations may result into offloading, interim storage and reloading of the products, combination of all these processes may expose the products to harsh conditions that could result into product deterioration/spoilage. A low-risk situation is shown by the existence of 1-2 delivery destinations and nodes; which do not need any reloading or interim storage. A high-risk situation is indicated by presence of more than two delivery destinations or nodes which need interim storage.

The nature of infrastructure is determined by the type of transport, road/railway conditions, and capacity of bridges and/ or ferries. Based on the type of transport, it is assumed that the faster the transportation processes the lesser the time products are exposed to harsh conditions (e.g. rain, temperature abuse). A low-risk situation is indicated by use of fast transportation methods like aircrafts, cars, ships and or trains, while a high-risk situation is specified by the use of carts pulled by draft animals and/ or manual transport. Disaster operations are normally carried out in an environment with destabilized infrastructures, ranging from a lack of electricity supplies to a limited transport infrastructure (Kovács and Spens, 2007), which can negatively affect quality of donated food if not properly controlled. Lastly, it is assumed that adequate and well-trained/educated personnel may handle products in a proper way; which positively contributes to the final quality. A low-risk situation prevails when there are adequate, welltrained/educated, competent and experienced personnel with food distribution during the emergencies, whereas, high-risk situation is associated with use of few people with limited education, competence and experience with food distribution during the emergencies.

\section{CONCLUSIONS}

The overall objective of this study was to develop a theoretical framework giving insights in the key-risk factors that could influence quality/safety of donated food along the food aid supply chains. Quality control in food aid supply chains may be challenging, because, in quick onset emergencies there is usually no warning between 
the time a demand occurs and the time the supplies are needed (Kovács and Spens, 2007; Beamon and Balcik, 2008). During this situation, enough resources (i.e. financial, human, equipment and other supplies) are required to control quality of donated food along the supply chain. However, most food aid receiving countries are developing countries characterised by limited resources to adequately respond to the needs during the emergencies and even to their normal local supplies. To ensure safety of donated food to the recipients; quality control needs combined efforts from different actors in the food aid supply chain. In addition, unlike the customers in commercial supply chains; food aid recipients in the food aid supply chains have no alternative when it comes to donated food. During the emergencies, people are desperately in need of food, thus quality and safety is not an issue of importance. Therefore, recipient countries' governments, international community and all other stakeholders in the food aid chain should effectively control quality of donated food, to ensure a safe supply to such a vulnerable population. This study provided insights on the key-risk quality/safety influencing factors and possible potential points along the food aid supply chains where quality and safety of products could be influenced and possible intervention measures that could be taken. It is useful to policy makers, national food control authorities and other stakeholders involved in the food aid supply chain.

\section{REFERENCES}

Anyanwu RC, Jukes DJ (1990). Food safety control systems for developing countries. Food Control 1(1): 17-26.

Anyanwu RC, Jukes DJ (1991). Food systems and food control in Nigeria. Food Policy 16(2): 112-126.

Barrett CB, Maxwell D (2007). Food aid after fifty years: recasting its role. Routledge

Barrett CB, Maxwell DG (2006). Towards a global food aid compact. Food Policy 31(2): 105-118.

Beamon BM, Balcik B (2008). Performance measurement in humanitarian relief chains. International Journal of Public Sector Management 21(1): 4-25.

Bezu S, Holden S (2008). Can food-for-work encourage agricultural production? Food Policy 33(6): 541-549.

Bourlieu C, Guillard V, Powell H, Vallès-Pàmies B, Guilbert S, Gontard $\mathrm{N}$ (2008). Modelling and control of moisture transfers in high, intermediate and low aw composite food. Food Chemistry 106(4): 1350-1358.

Codex Alimentarius Commission (2003). Guidelines for Food Import Control Systems. Document CAC/GL: 47-2003.

De Angelis V, Mecoli M, Nikoi C, Storchi G (2007). Multiperiod integrated routing and scheduling of World Food Programme cargo planes in Angola. Computers \& Operations Research 34(6): 16011615.

del Ninno C, Dorosh PA, Subbarao K (2007). Food aid, domestic policy and food security: Contrasting experiences from South Asia and sub-Saharan Africa. Food Policy 32(4): 413-435.

Dexter P (1996). Requirements for effective fortification in food aid programmes. FAO Food and Nutrition Paper 60: 77-91.

FAO/WHO (2003). Assuring food safety and quality. Guidelines for strengthening national food control systems. Food and Nutrition Paper 76:
FAO/WHO (2004). Developing and maintaining food safety control systems for Africa current status and prospects for change. In: Second $\mathrm{FAO}$ WHO global forum of food safety regulators, Bangkok, 12-24 ${ }^{\text {th }}$ October, 2004 2004. FAO, Rome, Italy, p 1-6.

Fleige LE, et al. (2010). Recommendations for optimization of fortified and blended food aid products from the United States. Nutrition Reviews 68(5): 290-315.

Gardner BL, Rausser GC (2002). Handbook of agricultural economics, vol 2. Elsevier

Garg T, Barrett CB, Gómez MI, Lentz EC, Violette WJ (2013). Market Prices and Food Aid Local and Regional Procurement and Distribution: A Multi-Country Analysis. World Development 49(0): 19-29.

Gelan AU (2007). Does food aid have disincentive effects on local production? A general equilibrium perspective on food aid in Ethiopia. Food Policy 32(4): 436-458.

Hale H (1999). Commodity management enhancement project: Food aid logistics operational handbook. CARE USA

Harou AP, Upton JB, Lentz EC, Barrett CB, Gómez MI (2013). Tradeoffs or Synergies? Assessing Local and Regional Food Aid Procurement through Case Studies in Burkina Faso and Guatemala. World Development 49(0): 44-57.

Harvey P, Proudlock K, Clay EJ, Riley B, Jaspars S (2010). Food aid and food assistance in emergency and transitional contexts: a review of current thinking. Humanitarian Policy Group, p 1-4.

Hoddinott J, Cohen MJ, Bos MS Food aid in the 21st century: Current issues and food aid as insurance. In: International Workshop on Defining the Role of Food Aid in Contributing to Sustainable Food Security, Berlin, Germany. September, 2003.

Hopper M, Boutrif E (2007). Strengthening National Food Control Systems: A Quick Guide to Assess Capacity Building Needs. Food and Agriculture Organisation

Jay JM, Loessner MJ, Golden DA (2008). Modern food microbiology. Springer Science \& Business Media

Käferstein $F$ (2003). Actions to reverse the upward curve of foodborne illness. Food Control 14(2): 101-109.

Kovács G, Spens K (2007). Humanitarian Logistics in Disaster Relief Operations. International Journal of Physical Distribution and Logistics Management 37(2): 99-114.

Kripke G (2005). Food Aid or Hidden Dumping Separating wheat from chaff. Oxfam Policy and Practice: Agriculture, Food and Land 5(1): 1-37.

Landman J Food aid in emergencies: a case for wheat? In: Proceedings of the Nutrition Society, 1999. vol 58. Cambridge Univ Press, London, p 355-361.

Leistner L, Gould GW (2002). Hurdle Technologies: Combination Treatments for Food Stability, Safety and Quality: Combination Treatments for Food Stability, Safety, and Quality. Springer Science \& Business Media

Lentz EC, Passarelli S, Barrett CB (2013). The timeliness and costeffectiveness of the local and regional procurement of food aid. World Development 49: 9-18.

Levinsohn J, McMillan M (2007). Does food aid harm the poor? Household evidence from Ethiopia Globalization and poverty. University of Chicago Press, p 561-598.

Luning PA, Marcelis WJ (2009). Food quality management: Technological and managerial principles and practices. Wageningen Academic Publishers, Wageningen.

Marchione TJ (2002). Foods provided through US Government Emergency Food Aid Programs: policies and customs governing their formulation, selection and distribution. The Journal of Nutrition 132(7): $2104 \mathrm{~S}-2111 \mathrm{~S}$.

Mathys E (2004). Community-Managed Targeting and Distribution of Food Aid: A review of the experience of Save the Children UK in sub-Saharan Africa. Save the Children, London, p 87.

Meulen B, van der Velde M, Szajkowska A, Verbruggen R (2008). European food law handbook. Wageningen: Wageningen Academic Publishers

Murphy S, McAfee K (2005). U.S. food aid: time to get it right Trade and global governance program. The Institute for Agriculture and Trade Policy, Minnesota, p 39. 
Mutukumira AN, Jukes DJ (2003). The development of national food safety control system in Sub-Saharan Africa - issues and opportunities. Paper presented at the Food Africa, Congress centre/palais de congress, Yaoundé, Cameroon, 5-9 May, 2003.

Neeliah SA, Goburdhun D (2007). National food control systems: a review. Food Reviews International 23(1): 35-51.

Neeliah SA, Goburdhun D, Neeliah H (2009). National food control systems: lessons from Mauritius. Ecology of food and nutrition 48(2): 137-156.

Nguz K (2007). Assessing food safety system in sub-Saharan countries: An overview of key issues. Food Control 18(2): 131-134.

Oloruntoba R, Gray R. (2006). Humanitarian aid: an agile supply chain? International Journal of Supply Chain Management 11(2): 115-120.

Özdamar L, Ekinci E, Küçükyazici B (2004). Emergency Logistics Planning in Natural Disasters. Annals of Operations Research 129(1-4): 217-245.

Pelham-Burn SE, Frost CJ, Russell JM, Barker ME (2014). Improving the nutritional quality of charitable meals for homeless and vulnerable adults. A case study of food provision by a food aid organisation in the UK. Appetite 82(0): 131-137.

Rahman MS (2007). Handbook of food preservation. CRC press

Rancourt M, Cordeau J, Laporte G, Watkins B (2015). Tactical networking planning for food aid distribution in Kenya. Computer and Operations Research 56: 68-83.

Reed BA, Habicht J-P (1998). Sales of food aid as sign of distress, not excess. The Lancet 351(9096): 128-130.

Rupiya MR (2004). Food aid. African Security Review 13(1): 83-89.

Stevenson C (1995). Monduli Food Aid Programme: A manual of food relief procedures and drought preparedness activities. Dar es Salaam

Stewart J (2003). Moving food: The world food programme's response to the Southern African humanitarian crisis. African Security Studies 12(1): 17-27.

Taoukis PS, Labuza TP, Saguy IS (1997). Kinetics of food deterioration and shelf-life prediction. In: Valentas K.J., E. R (eds) Handbook of food engineering practice. CRC Press Boca Raton, FL, p 361-403.

Taub IA, Singh RP (2010). Food storage stability. CRC Press

Tusiime HA, Renard R, Smets L (2013). Food aid and household food security in a conflict situation: Empirical evidence from Northern Uganda. Food Policy 43(0): 14-22.
United States Government Accountability Office (2011). International food assistance: Better Nutrition and Quality Control Can Further Improve U.S. Food Aid. United States Government Accountability Office, Washington, DC, p 74.

Varzakas TH, Tsigarida ET, Apostolopoulos C, Kalogridou-Vassiliadou D, Jukes DJ (2006). The role of the Hellenic Food Safety Authority in Greece-Implementation strategies. Food Control 17(12): 957965.

Violette WJ, et al. (2013). Recipients' Satisfaction with Locally Procured Food Aid Rations: Comparative Evidence from a Three Country Matched Survey. World Development 49(0): 30-43.

Vytelingum S (2003). National food control systems: a case-study of Mauritius.

Wareing P, Boxall R, Gough M, Phillips S (1993). Changes in the mycoflora of UK wheat shipped to tropical regions. International Biodeterioration \& Biodegradation 32(1): 175-185.

Webb, et al. (2011). Improving the Nutritional Quality of U.S. Food Aid: Recommendations for Changes to Products and Programs Tufts University, Boston, MA

Webb P (2003). Food as aid: trends, needs and challenges in the 21st century. World Food Programme, Strategy and Policy Division

Whitehead A (1995). Elements of an effective national food control system. Food Control 6(5): 247-251.

World Packaging Organisation (2009). Position paper- Packaging and food safety. In: WPO. www.worldpackaging.org Accessed 27 May 2015.

Young LM, Abbott PC (2005). The WTO Negotiations and Disciplines for Food Aid. Bridges 9(5): 3-5.

Zant W (2012). The economics of food aid under subsistence farming with an application to Malawi. Food Policy 37(1): 124-141.

Zerbe N (2004). Feeding the famine? American food aid and the GMO debate in Southern Africa. Food Policy 29(6): 593-608. 